\title{
South African guideline for the use of chronic opioid therapy for chronic non-cancer pain
}

\author{
M Raff, ${ }^{1}$ BSc, MB ChB, FCA (SA); J Crosier, ${ }^{1}$ MB ChB, ChM, FRCS, FCS (SA); S Eppel, ${ }^{1}$ MB ChB, FRCS (Edin), ABU (USA); \\ Christiaan Barnard Memorial Hospital, Cape Town, South Africa \\ ${ }^{2}$ Department of Family Medicine, Faculty of Health Sciences, University of Pretoria, South Africa \\ ${ }^{3}$ Rheumatic Diseases Unit, Groote Schuur Hospital, Cape Town, South Africa \\ ${ }^{4}$ Pattacus Medical Consulting, Johannesburg, South Africa
}

H Meyer, ${ }^{2}$ MB ChB, MPraxMed, MFGP (SA), FCFP (SA); B Sarembock, ${ }^{1,3}$ MB ChB, FCP (SA), RHEUM (SA); D Webb ${ }^{4}$ BSc (Hons), MB ChB

Corresponding author: M Raff (raffs@iafrica.com)

This guideline is endorsed by the following professional groups: Cape Pelvic Pain Society, PainSA, South African Rheumatism and Arthritis Association, and South African Society of Anaesthesiologists.

Disclaimer. While every effort has been made to ensure the accuracy of the contents at the time of publication, the authors do not guarantee the accuracy of the information contained nor accept any liability, with respect to loss, damage, injury or expense, arising from any errors or omissions in the contents of this work. Reference in the guideline to specific pharmaceutical products does not imply endorsement of any of these products

\section{Quick Reference Guide}

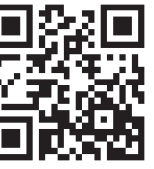

\section{General management}

- Chronic non-cancer pain (CNCP) is defined as pain lasting for $>90$ days and beyond the expected time for tissue healing.

- $\mathrm{CNCP}$ is often associated with psychological comorbidities (anxiety and depression) and limitation of physical function.

- Management of CNCP requires a multimodal, multidisciplinary approach to address:

- pain and comorbidities

- psychological issues

- functional rehabilitation

- social issues.

- Patients should be referred to specialist practitioners for interventions when appropriate, and thereafter referred back to the general practitioner for continued care.

- Communication between the patient's healthcare team is mandatory to establish roles and expectations for continuity of care and safe use of opioids.

- Patients should identify with one doctor (usually the general practitioner) who accepts primary responsibility for their overall medical care and who should coordinate communication and consultation among clinicians.

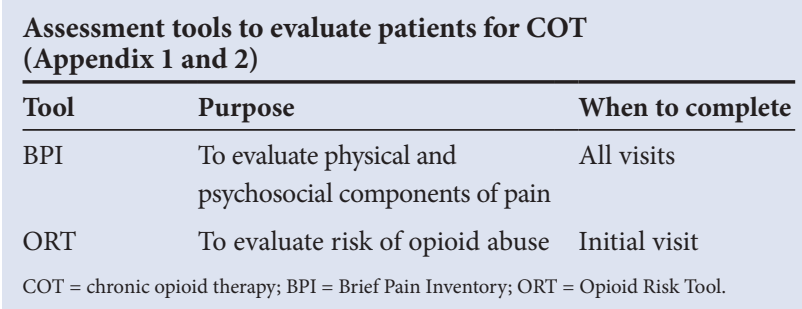

- To help ensure correct use of medication and to reduce prescription fraud, all opioids (and preferably all other medications) for a particular patient should be dispensed through a single designated pharmacy.

- Chronic opioid therapy (COT) is defined as regular use of strong opioids for at least 3 months.

\section{Indications for opioids}

- Opioids may be appropriate in carefully selected patients with moderate to severe pain, which:

- significantly and adversely affects quality of life, or

- has not responded to non-pharmacological and non-opioid pharmacological therapies.

- Opioids are not appropriate as the primary medication of choice for pain disorders with strong psychosocial contributing factors.

\section{Before initiating COT}

- Establish a diagnosis and the cause of the pain.

- Estimate the pain intensity and functional impairment.

- Risk stratify the patient in terms of potential benefits and harms of opioid therapy to assess their suitability for COT.

\subsection{Patient assessment and diagnosis}

- Patient's pain disorder

- Pain intensity

- Functional impairment (impact of pain on work, school/studying, home and leisure activities)

- General medical condition

- Sleeping pattern

- Psychosocial history (living arrangements, family/social support, family obligations, work status)

- Psychiatric status

- Substance use history

- Other medications 
3.2 Explain treatment options and address expectations

- Total pain relief is rarely achieved.

- Goals of therapy are pain reduction and functional improvement:

- Clinically meaningful improvement is at least $30 \%$ reduction in pain (or $\geq 2$ points on a 0 - 10 numerical rating scale) and/or $30 \%$ improvement in function.

- Caution patients against unrealistic expectations.

- Potential benefits, adverse effects, complications and risks of COT.

- Alternatives to COT.

- Consider asking the patient to sign an opioid agreement (Appendix 3).

- Initial course of COT is viewed as a short-term trial, which will be continued if response is satisfactory.

- Positive clinical response to COT may take a few days to become apparent.

Detailed notes of all assessments, discussions and treatment decisions should be maintained at all visits.

\section{Choice of opioid}

- Opioid analgesics for CNCP may be administered orally or transdermally.

- When choosing an appropriate opioid, consider health status, pain severity, previous exposure to opioids, attainment of therapeutic goals and predicted or observed harms, concomitant medications.

- Use immediate release (IR) oral opioids to initiate therapy and titrate to an effective dose.

- Once pain control is stable, if possible, switch to long-acting (controlled release (CR); extended release (ER), sustained release (SR)) oral opioid or transdermal opioid patch.

\section{Initiation and titration of COT}

- Start with a low dose: $\leq 10 \mathrm{mg} /$ day oral morphine equivalents.

- Reassess dose after $72 \mathrm{~h}$ (clinical improvement and tolerability).

- Dose may be slowly increased by not more than $10 \mathrm{mg}$ morphine equivalents per day over 4 - 6 weeks.

- Maximum daily dose should preferably not exceed $90 \mathrm{mg}$ oral morphine equivalents.

- If repeated dose escalations are required, consider:

- increase in the intensity of the underlying pain condition (disease progression)

- development of an additional painful condition

- opioid tolerance

- opioid-induced hyperalgesia

- drug abuse (e.g. recreational use).

\section{Step-wise approach to opioid selection}

\begin{tabular}{llll}
\hline & Mild-to-moderate pain & & Severe pain \\
\cline { 1 - 2 } $\begin{array}{l}\text { First-line } \\
\text { Second-line }\end{array}$ & $\begin{array}{l}\text { Codeine or tramadol } \\
\text { Morphine, low-dose oxycodone, dihydrocodeine, } \\
\text { hydromorphone or buprenorphine }\end{array}$ & & $\begin{array}{l}\text { Morphine, high-dose oxycodone, hydromorphone, or buprenorphine } \\
\text { Fentanyl }\end{array}$
\end{tabular}

Oral opioids: Suggested initial dose and titration ${ }^{*,+}$

\begin{tabular}{|c|c|c|c|c|}
\hline Opioid & Initial dose & $\begin{array}{l}\text { Min. time interval for } \\
\text { increase (days) }\end{array}$ & Suggested dose increase & $\begin{array}{l}\text { Min. daily dose before } \\
\text { converting IR to CR }\end{array}$ \\
\hline $\begin{array}{l}\text { Codeine (alone/ } \\
\text { in combination with } \\
\text { paracetamol/ASA) }\end{array}$ & $\begin{array}{l}15 \text { - } 30 \mathrm{mg} \text { 4-hourly as } \\
\text { required }\end{array}$ & 7 & $\begin{array}{l}15-30 \mathrm{mg} / \text { day, } \\
\max .600 \mathrm{mg} / \text { day }^{*}\end{array}$ & $100 \mathrm{mg}$ \\
\hline $\begin{array}{l}\text { Tramadol }(37.5 \mathrm{mg})+ \\
\text { paracetamol }(325 \mathrm{mg})\end{array}$ & 1 tablet 4 -6-hourly & 7 & $\begin{array}{l}1 \text { - } 2 \text { tablets } 4 \text { - } 6 \text {-hourly as } \\
\text { needed, max. } 8 \text { tablets/day }\end{array}$ & 3 tablets \\
\hline Tramadol & 50 mg 4 - 6-hourly & & Max. dose: $400 \mathrm{mg} /$ day & NA \\
\hline SR tramadol & 100 mg 12-hourly & 2 & Max. dose: $400 \mathrm{mg} /$ day & NA \\
\hline IR morphine & $\begin{array}{l}5 \text { - } 10 \mathrm{mg} \text { 4-hourly as } \\
\text { needed, max. } 40 \mathrm{mg} / \\
\text { day }\end{array}$ & 7 & $5-10 \mathrm{mg} /$ day & $20-30 \mathrm{mg}$ \\
\hline CR morphine & 10 - 30 mg 12-hourly & Min. 2, recommended: 14 & $5-10 \mathrm{mg} /$ day & NA \\
\hline IR oxycodone & $\begin{array}{l}5 \text { - } 10 \mathrm{mg} \text { 6-hourly as } \\
\text { needed, max. } 40 \mathrm{mg} / \\
\text { day }\end{array}$ & 7 & $5 \mathrm{mg} /$ day & $20 \mathrm{mg}$ \\
\hline CR oxycodone & $\begin{array}{l}10 \text { - } 20 \mathrm{mg} \text { 12-hourly, } \\
\max .40 \mathrm{mg} / \text { day }\end{array}$ & Min. 2, recommended: 14 & $10 \mathrm{mg} /$ day & NA \\
\hline ER hydromorphone & $\begin{array}{l}4 \mathrm{mg} \text { daily, max. } 16 \mathrm{mg} / \\
\text { day }\end{array}$ & Min. 2, recommended: 14 & $2-4 \mathrm{mg} /$ day & NA \\
\hline Dihydrocodeine & 30 mg 6-hourly & Min. 2, recommended: 7 & $\begin{array}{l}\text { Increase to } 30 \mathrm{mg} \text { every } 4 \mathrm{~h} \text {, } \\
\text { max. } 240 \mathrm{mg} / \text { day }\end{array}$ & NA \\
\hline \multicolumn{5}{|c|}{$\begin{array}{l}\text { IR = immediate release; } \mathrm{CR}=\text { controlled release; } \mathrm{ASA}=\text { acetylsalicylic acid; } \mathrm{ER}=\text { extended release; } \mathrm{SR}=\text { sustained release. } \\
{ }^{*} \text { Modified from the Canadian National Opioid Use Guideline Group }(2010){ }^{[4]} \\
{ }^{+} \text {Due to a genetic polymorphism that influences the response to opioid analgesics, there is inter-individual variation in the doses required for adequate analgesia. Some patients will require } \\
\text { considerably higher opioid doses than others. }\end{array}$} \\
\hline
\end{tabular}


Equianalgesic doses for conversion from one oral opioid to another ${ }^{*, t}$

\begin{tabular}{|c|c|c|c|}
\hline \multirow[b]{2}{*}{ Opioid } & \multirow[b]{2}{*}{ Equivalence to $30 \mathrm{mg}$ morphine $(\mathrm{mg})$} & \multicolumn{2}{|c|}{ Conversion to/from oral morphine equivalent - multiply by } \\
\hline & & To & From \\
\hline Morphine & 30 & 1 & 1 \\
\hline Codeine & 200 & 0.15 & 6.67 \\
\hline Oxycodone & 20 & 1.5 & 0.67 \\
\hline Hydromorphone & 6 & 5 & 0.2 \\
\hline Dihydrocodeine & 180 & 0.16 & 6 \\
\hline Tramadol & \multicolumn{3}{|l|}{$\sim 1: 10^{\ddagger}$} \\
\hline
\end{tabular}

Approximate equipotent doses for conversion from oral morphine to transdermal opioids

\begin{tabular}{|c|c|c|c|c|c|c|c|c|}
\hline \multicolumn{9}{|l|}{ Oral morphine to transdermal fentanyl $l^{*,+}$} \\
\hline Oral morphine equivalent (mg/24 h) & $60-134$ & $135-179$ & $180-224$ & $225-269$ & $270-314$ & $315-359$ & \multicolumn{2}{|l|}{$360-404$} \\
\hline Transdermal fentanyl $(\mu \mathrm{g} / \mathrm{h})^{\ddagger}$ & 25 & 37 & 50 & 62 & 75 & 87 & \multicolumn{2}{|l|}{100} \\
\hline \multicolumn{9}{|c|}{ Oral morphine to transdermal buprenorphine ${ }^{\S, 9}$} \\
\hline Oral morphine equivalent (mg/24 h) & 10 & 15 & 30 & 60 & 90 & 120 & 180 & 240 \\
\hline Transdermal buprenorphine $(\mu \mathrm{g} / \mathrm{h})$ & 5 & 10 & 20 & 35 & 52.5 & 70 & 105 & 140 \\
\hline \multicolumn{9}{|c|}{$\begin{array}{l}{ }^{*} \text { Adapted from the Canadian National Opioid Use Guideline Group }(2010) \cdot{ }^{[4]} \\
{ }^{+} \text {Conversion rate is } 150: 11^{[6]} \text { e.g. } 120 \mathrm{mg} \text { morphine over } 24 \mathrm{~h}: 120 \div 150=0.8 \mathrm{mg} \text { fentanyl; } 0.8 \times 1000=800 \mu \mathrm{g} \text { fentanyl over } 24 \mathrm{~h}=33.3 \mu \mathrm{g} / \mathrm{h} \text {. Round up or down to appropriate patch. } \\
{ }^{*} \text { Formulations include } 12,25,50,75 \mathrm{and} 100 \mu \mathrm{g} / \mathrm{h} \text { patches, but the } 12 \mu \mathrm{g} / \mathrm{h} \text { patch is generally used for dose adjustment rather than initiation of fentanyl treatment. } \\
\text { "Adapted from the British Pain Society }(2010) .\left[{ }^{[2]}\right.\end{array}$} \\
\hline
\end{tabular}

Common opioid-related adverse effects and their management

\begin{tabular}{ll}
\hline Adverse effect & Management \\
\hline Nausea/vomiting & $\begin{array}{l}\text { Anti-emetic therapies (oral or suppository); it is advisable to concurrently prescribe a prophylactic anti-emetic } \\
\text { for a few days when initiating opioid therapy }\end{array}$ \\
Constipation & $\begin{array}{l}\text { Increase fluid and fibre intake; stool softeners; laxatives } \\
\text { Pruritus }\end{array}$ \\
Antihistamine \\
Sedation, clouded mentation
\end{tabular}

\section{Consider switching to another opioid if:}

- Analgesia is inadequate despite dose escalation

- Adverse effects are intolerable

- Stable pain control is achieved on IR opioid and it is appropriate to switch to a long-acting formulation or transdermal opioid patch.

\section{Breakthrough pain}

- Consider as-needed IR opioid for rescue analgesia.

- If continuous rescue doses are required, up-titrate maintenance analgesic dose by adding the extra dose per day required for breakthrough pain.

\section{Long-term opioid prescribing}

When a trial of opioid has been successful, treatment may be continued until:

- the underlying painful condition resolves

- the patient receives a definitive pain relieving intervention (e.g. joint replacement)
- the patient no longer derives benefit from opioid treatment

- the patient develops intolerable side-effects; or

- there is evidence of addiction, tolerance, dependence or opioid-induced hyperalgesia. It should be noted that patients who are suffering with severe pain rarely become addicted to opioids. They may require increasing doses of opioids as a result of opioid tolerance and this must be differentiated from addiction.

\section{Discontinuing opioids}

- Reduce dose slowly by approximately $10 \%$ per day or per week.

- Dose should be tapered more slowly in patients who are anxious about discontinuing COT and in those who are suspected of being physically dependent on opioids.

- When one-third of the original dose is reached, reduce the rate of tapering to one-half or less of the initial rate.

- If the patient experiences withdrawal symptoms or an increase in pain during tapering, discontinue dose reduction and consider increasing the current dose. 
Clinical features of opioid toxicity and withdrawal

\begin{tabular}{|c|c|}
\hline & Symptoms \\
\hline \multirow[t]{9}{*}{ Toxicity } & Pinpoint pupils \\
\hline & $\begin{array}{l}\text { Sedation (falling asleep during } \\
\text { conversation or activity) }\end{array}$ \\
\hline & Slow respiration \\
\hline & $\begin{array}{l}\text { Visible cyanosis, e.g. lips, ears, nose (in } \\
\text { severe cases) }\end{array}$ \\
\hline & Myoclonic jerks \\
\hline & Snoring when asleep \\
\hline & Agitation \\
\hline & Confusion \\
\hline & $\begin{array}{l}\text { Vivid dreams, nightmares or } \\
\text { hallucinations }\end{array}$ \\
\hline \multirow[t]{3}{*}{ In more severe cases } & Hypotension \\
\hline & Coma \\
\hline & Convulsions \\
\hline \multirow[t]{12}{*}{ Withdrawal } & Sweating \\
\hline & Mydriasis \\
\hline & Pilo-erection \\
\hline & Yawning \\
\hline & $\begin{array}{l}\text { Abdominal cramps/vomiting/ } \\
\text { diarrhoea }\end{array}$ \\
\hline & Bone and muscle pain \\
\hline & Increase in usual pain \\
\hline & Restlessness \\
\hline & Anxiety \\
\hline & Rhinorrhoea \\
\hline & Lacrimation \\
\hline & Tremor \\
\hline
\end{tabular}

\section{Opioid-related adverse effects}

Adverse effects are usually manageable and most pronounced when initiating or increasing the dose.

10.1 For intolerable adverse effects, consider

- Reducing the opioid dose.

- Switching to another opioid formulation or route of administration.

- Discontinuing the opioid and instituting alternative pain management strategies.

\section{Driving and working while on opioids}

Patients should be advised to avoid driving, working under hazardous conditions or working with hazardous machinery if:

- the condition for which they are being treated has physical consequences that might impair their driving ability, concentration or coordination

- they feel unfit to drive or work

- they have constant severe pain

- they have not been sleeping

- they have just started opioid treatment

- their dose of opioids has been recently adjusted upwards or downwards (as withdrawal may have an impact on capability)

- they have consumed alcohol or other drugs that can produce an additive sedative effect.

\section{When to refer to a pain clinician or multidisciplinary pain unit}

- Unable to make a definite diagnosis of the cause of pain

- Significant comorbidities or other factors that may complicate opioid use (e.g. psychiatric comorbidities, severe renal impairment, etc.)

- Inadequate response to opioid analgesia, despite titration to $90 \mathrm{mg} /$ day oral morphine equivalent

- Unmanageable opioid-related side-effects

- Indications of inappropriate drug use. 


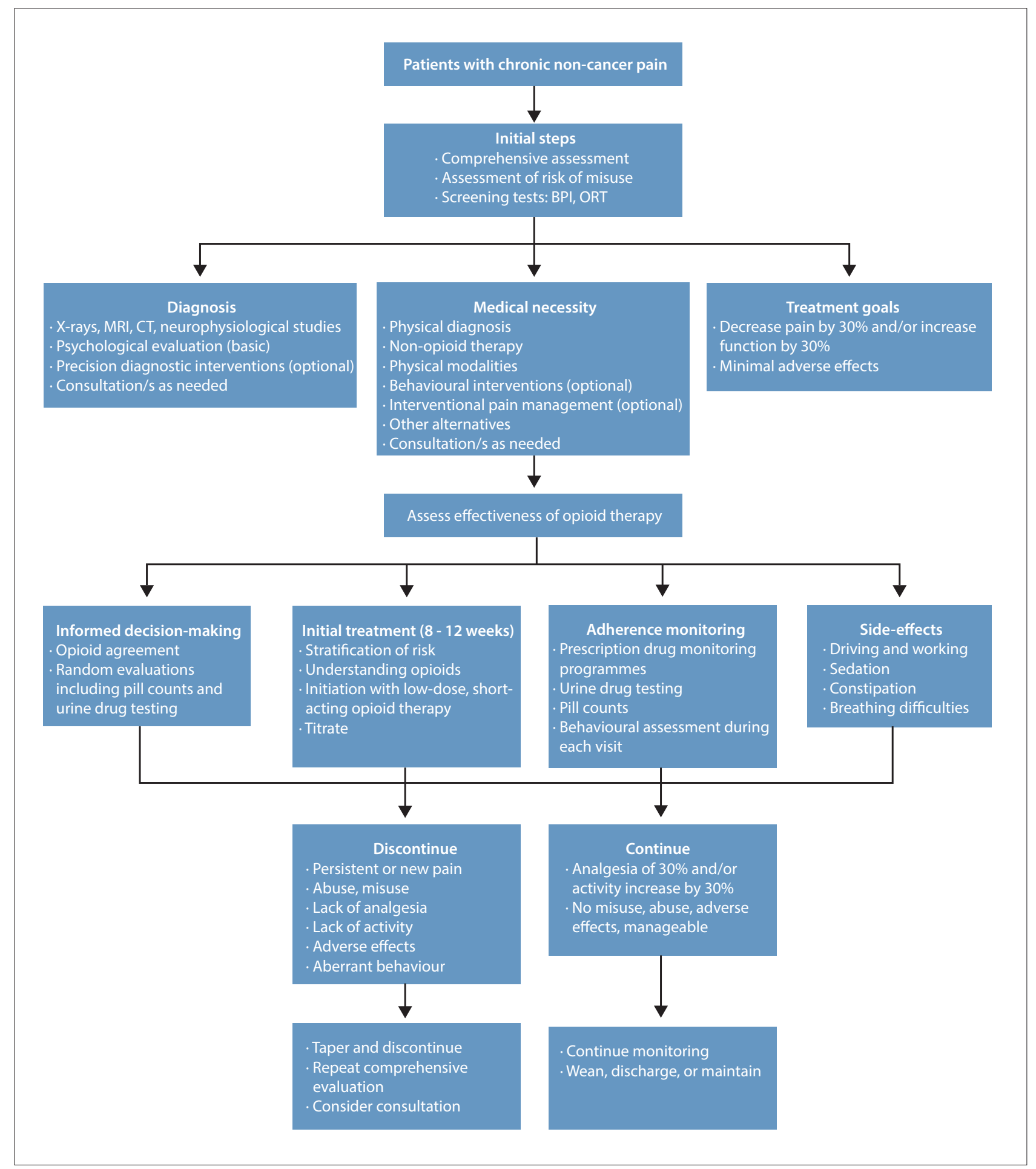

Algorithm for the initiation and use of COT. Adapted with permission from Manchikanti et al. ${ }^{[5]}$ (COT = chronic opioid therapy; BPI = Brief Pain Inventory; ORT = Opioid Risk Tool; $M R I=$ magnetic resonance imaging; $C T$ = computed tomography.) 


\section{Appendix 1. Brief Pain Inventory}

Name:

Date:

Time:

1. Throughout our lives, most of us have had pain from time to time (such as minor headaches, sprains and toothaches). Have you had pain other than these everyday kinds of pain today?
$\square$ YES
$\square \mathrm{NO}$

2. On the diagram, shade the area where you feel pain. Put an $\mathrm{X}$ on the area that hurts the most.

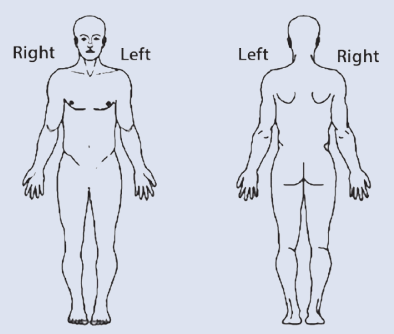

3. Please rate your pain by circling the number that best describes your pain at its worst in the past $24 \mathrm{~h}$.

$\begin{array}{lllllllllll}0 & 1 & 2 & 3 & 4 & 5 & 6 & 7 & 8 & 9 & 10\end{array}$

No pain Pain as bad as you can imagine

4. Please rate your pain by circling the number that best describes your pain at its least in the past $24 \mathrm{~h}$.

$\begin{array}{lllllllllll}0 & 1 & 2 & 3 & 4 & 5 & 6 & 7 & 8 & 9 & 10\end{array}$

No pain Pain as bad as you can imagine

5. Please rate your pain by circling the number that best describes your pain on average.

$\begin{array}{lllllllllll}0 & 1 & 2 & 3 & 4 & 5 & 6 & 7 & 8 & 9 & 10\end{array}$

No pain Pain as bad as you can imagine

6. Please rate your pain by circling the number that tells how much pain you have right now.

$\begin{array}{lllllllllll}0 & 1 & 2 & 3 & 4 & 5 & 6 & 7 & 8 & 9 & 10\end{array}$

No pain

Pain as bad as you can imagine
7. What treatments or medications are you receiving for your pain?

8. In the past $24 \mathrm{~h}$, how much relief have pain treatments or medications provided? Please circle the percentage that shows how much relief you have received.

$\begin{array}{lllllllllll}0 \% & 10 \% & 20 \% & 30 \% & 40 \% & 50 \% & 60 \% & 70 \% & 80 \% & 90 \% & 100 \%\end{array}$ No relief Complete relief

9. Circle the number that describes how, during the past $24 \mathrm{~h}$, pain has interfered with your:

A. General activity

$\begin{array}{lllllllllll}0 & 1 & 2 & 3 & 4 & 5 & 6 & 7 & 8 & 9 & 10\end{array}$

Does not interfere Completely interferes

B. Mood

$\begin{array}{lllllllllll}0 & 1 & 2 & 3 & 4 & 5 & 6 & 7 & 8 & 9 & 10\end{array}$

Does not interfere Completely interferes

C. Walking ability

$\begin{array}{lllllllllll}0 & 1 & 2 & 3 & 4 & 5 & 6 & 7 & 8 & 9 & 10\end{array}$

Does not interfere Completely interferes

D. Normal work (includes both work outside the home and housework)

$\begin{array}{lllllllllll}0 & 1 & 2 & 3 & 4 & 5 & 6 & 7 & 8 & 9 & 10\end{array}$

Does not interfere Completely interferes

E. Relations with other people

$\begin{array}{lllllllllll}0 & 1 & 2 & 3 & 4 & 5 & 6 & 7 & 8 & 9 & 10\end{array}$

Does not interfere Completely interferes

F. Sleep

$\begin{array}{lllllllllll}0 & 1 & 2 & 3 & 4 & 5 & 6 & 7 & 8 & 9 & 10\end{array}$

Does not interfere

Completely interferes

G. Enjoyment of Life

$\begin{array}{lllllllllll}0 & 1 & 2 & 3 & 4 & 5 & 6 & 7 & 8 & 9 & 10\end{array}$

Does not interfere

Completely interferes

${ }^{*}$ Reproduced with permission from Dr Charles S Cleeland (1991). 


\begin{tabular}{|c|c|c|}
\hline Risk factor & Male, score (max. score) & Female, score (max. score) \\
\hline \multicolumn{3}{|l|}{ Family history (parents and siblings) } \\
\hline Alcohol abuse & - (3) & _(1) \\
\hline Illegal drug use & _(3) & _(2) \\
\hline Prescription drug abuse & _(4) & _(4) \\
\hline \multicolumn{3}{|l|}{ Personal history } \\
\hline Alcohol abuse & _(3) & _(3) \\
\hline Illegal drug use & _(4) & _(4) \\
\hline Prescription drug abuse & _(5) & _(5) \\
\hline \multicolumn{3}{|l|}{ Mental health } \\
\hline Diagnosis of ADD, OCD, bipolar disorder or schizophrenia & _(2) & _(2) \\
\hline Diagnosis of depression & _(1) & _(1) \\
\hline \multicolumn{3}{|l|}{ Other } \\
\hline Age 16 - 45 years & _(1) & _(1) \\
\hline \multirow[t]{2}{*}{ History of pre-adolescent sexual abuse } & _(0) & _(3) \\
\hline & & \\
\hline \multicolumn{3}{|l|}{ Total score risk category: } \\
\hline \multicolumn{3}{|l|}{$0-3=$ low risk: $6 \%$ chance of developing problematic behaviours } \\
\hline \multicolumn{3}{|c|}{$4-7=$ moderate risk: $28 \%$ chance of developing problematic behaviours } \\
\hline \multicolumn{3}{|c|}{$\geq 8=$ high risk: $>90 \%$ chance of developing problematic behaviours } \\
\hline $\begin{array}{l}\mathrm{ADD}=\text { attention deficit disorder; } \mathrm{OCD}=\text { obsessive-compulsive disorder. } \\
\left.{ }^{*} \text { Reproduced with permission from Webster LR and Webster RM. }{ }^{.31}\right]^{\prime}\end{array}$ & & \\
\hline
\end{tabular}

\section{Appendix 3. Sample opioid agreement}

I (patient's name) understand that Dr is prescribing opioid medication for me to treat my chronic pain.

The opioid medication that has been prescribed is:

The risks and benefits of this medicine have been explained to me and I understand the following:

- the medicine may have certain side-effects including, but not limited to, drowsiness, dizziness, loss of coordination, constipation, nausea, vomiting and itching

- the medication may impair my ability to drive a motor vehicle, operate hazardous machinery or work under hazardous conditions

- alcohol and certain other medications may increase the risk of side-effects while I am taking opioid medication, or may reduce the effectiveness of my pain medication

- although the risk is low, addiction to opioid medication can occur; addiction is more likely to occur in people with a personal or family history of drug or alcohol abuse and/or addiction

- physical dependence to opioid medication may occur and may result in withdrawal symptoms if the medication is stopped abruptly

- opioid medication may not provide complete pain relief; if the pain or ability to be active does not improve after a reasonable trial of opioid medication, the medication may be stopped.

I agree to the following:

1. Only Dr will prescribe opioids for me, and I will not seek or accept opioid medications from anyone else.

2. I will take my opioid medication exactly as instructed by $\mathrm{Dr}$ and will not take it in larger doses or more frequently than instructed.

3. I will tell Dr about all other medications I am taking and about any personal/family history of alcohol/drug abuse or illegal drug activity. I will not use any other prescribed or over-the-counter medication without discussing it with him/her first.

4. I will not give my opioid medication to anyone else and I will store it in a safe and secure place and out of the reach of children.

5. (Females only) I will tell my doctor immediately if I am planning to become pregnant or if I think that I am or might be pregnant.

6. My medical practitioner may decide to discontinue my opioid medication if my pain or ability to be active does not improve, or if I do not comply with any of the above.

Patient signature: Date: Witness: 